\title{
Desain Perangkat Lunak Berbasis Jaringan Syaraf Tiruan Backpropagation untuk Klasifikasi Citra Rontgen Paru-paru
}

\author{
M. Arief Bustomi, ${ }^{1},{ }^{*}$ Hasan Bisri, ${ }^{1}$ dan Endah Purwanti ${ }^{2}$ \\ ${ }^{1}$ Jurusan Fisika-FMIPA, Institut Teknologi Sepuluh Nopember \\ Kampus ITS Sukolilo, Surabaya 61111 \\ ${ }^{2}$ Departemen Fisika-FST, Universitas Airlangga \\ Kampus C Unair Mulyorejo, Surabaya 60115
}

Intisari

\begin{abstract}
Paper ini menyajikan hasil analisis sebuah desain perangkat lunak berbasis jaringan syaraf tiruan backpropagation untuk mengklasifikasikan citra rontgen paru-paru. Citra rontgen paru-paru yang akan diklasifikasi harus melalui pemrosesan awal terlebih dahulu untuk membuang informasi yang tidak dibutuhkan agar kualitas citra dapat ditingkatkan. Untuk keperluan klasifikasi citra rontgen paru-paru ke dalam kelompok tertentu, digunakan proses ekstraksi fitur histogram pada citra rontgen paru-paru tersebut. Setelah sistem perangkat lunak dibuat, dua tahapan penting berikutnya adalah pelatihan dan pengujian pada sistem perangkat lunak tersebut. Dalam penelitian ini, desain perangkat lunak hanya dibatasi untuk dapat mengklasifikasikan citra rontgen ke dalam tiga kelompok yaitu citra rontgen paru-paru normal, citra rontgen paru-paru terkena kanker, dan citra rontgen paru-paru terkena efusi. Hasil pengujian memperlihatkan bahwa performansi sistem perangkat lunak yang telah dibuat dengan parameter epoch 500, error 0.001 , learning rate 0.1 dan jumlah neuron 2500 ternyata memiliki tingkat akurasi sebesar $65 \%$.
\end{abstract}

\begin{abstract}
This paper presents the results of analysis of a software design based backpropagation neural network to classify the X-ray image of the lungs. X-ray image of the lungs should be classified through initial processing prior to discard unneeded information that the image quality can be improved. For the purposes of classification of lung $\mathrm{X}$-ray image into a particular group, use the histogram feature extraction process in X-ray image of the lungs . Once the software system is made, the next important step is two training and testing on the software system. In this study, the design of the software is limited to X-ray image can classify into three groups, namely X-ray image of a normal lung, X-ray image of the lung cancer, and the X-ray image of lungs affected by effusion. The test results show that the performance of software systems that have been created with 500 epoch parameters, error $0001,0.1$ learning rate and the number of neurons in 2500 turned out to have an accuracy rate of $65 \%$.
\end{abstract}

KATA KUNCI: image classification, backpropagation artificial neural network, feature extraction histogram, grayscale image of the lungs

\section{PENDAHULUAN}

Pengolahan citra dapat diaplikasikan dalam bidang medis untuk membantu dokter dalam mendiagnosa suatu penyakit. Pengolahan citra digital dalam bidang medis mengalami kemajuan penting ketika ditemukan metode tomografi terkomputerisasi (computerized tomography/ CT) pada tahun 1970an [1]. Kini teknologi tomografi sudah berkembang pesat sekali. Beberapa contoh penerapan pengolahan citra untuk diagnosis penyakit, misalnya adalah untuk keperluan identifikasi tumor atau kanker rahim, identifikasi penyakit paru-

*E-MAIL: a_bustomi@physics.its.ac.id paru, identifikasi penyakit hati, identifikasi penyakit tulang, dan lain sebagainya [2].

Makalah ini akan memaparkan sebuah aplikasi pengolahan citra untuk membantu dokter dalam menentukan jenis penyakit paru-paru. Dalam makalah ini pengklasifikasian paru-paru hanya dibatasi pada paru-paru normal, paru-paru yang terkena efusi, atau paru-paru yang terkena kanker [3-5].

Tujuan dari penelitian dalam makalah ini adalah untuk menghasilkan suatu sistem perangkat lunak yang dapat mengklasifikasikan citra paru-paru ke dalam tipe kanker, normal atau efusi serta menganalisa performansi sistem perangkat lunak yang telah dibuat tersebut. 


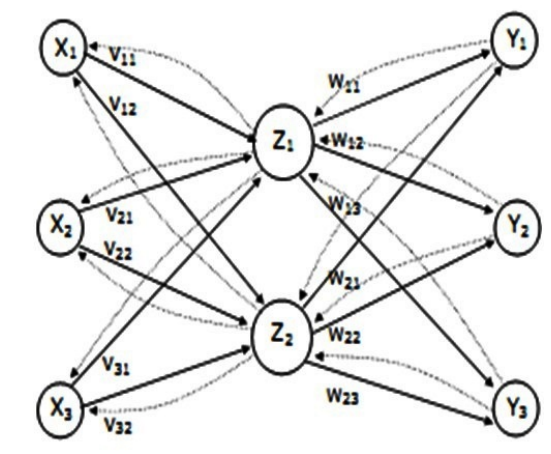

Gambar 1: Arsitektur Jaringan backpropagation.

\section{DASAR TEORI}

\section{Pengolahan Citra}

Suatu citra dapat didefinisikan sebagai fungsi $f(x, y)$ berukuran $\mathrm{M}$ baris dan $\mathrm{N}$ kolom, dengan $\mathrm{x}$ dan $\mathrm{y}$ adalah koordinat spasial dan amplitude $\mathrm{f}$ di titik koordinat $(\mathrm{x}, \mathrm{y})$ adalah intensitas atau tingkat keabuaan dari citra pada titik tersebut. Apabila nilai amplitude f secara keseluruhan berhingga (finite) dan bernilai diskrit maka dapat dikatakan bahwa citra tersebut adalah citra digital [1].

Pengolahan citra merupakan suatu cara untuk mengolah citra sehingga dihasilkan citra yang kualitasnya lebih baik sesuai dengan keinginan. Operasi-operasi yang diterapkan dalam pengolahan citra dapat bertujuan untuk keperluan perbaikan citra, modifikasi citra, pengelompokan citra, penggabungan citra, dan lain-lain $[6,7]$.

\section{Jaringan Syaraf Tiruan Backpropagation}

Jaringan Saraf Tiruan (JST) merupakan suatu metode komputasi yang mencoba untuk meniru cara kerja jaringan syaraf. Otak manusia yang merupakan sebuah sistem jaringan syaraf mempunyai kemampuan menyimpan, mengenal dan menirukan sesuatu bila kepadanya diberikan sebuah proses pembelajaran. Setelah menjalani proses pembelajaran, otak manusia dapat digunakan untuk melakukan berbagai hal yang mirip dengan yang dilakukannya dalam proses pembelajaran. Metode komputasi jaringan syaraf tiruan, mencoba mengimplementasikan kerja jaringan syaraf dalam komputasi, dimana akan ada proses pembelajaran terlebih dahulu, sebelum sistem komputasi tersebut digunakan [8,9].

backpropagation merupakan algoritma pembelajaran yang terawasi dan biasanya digunakan oleh perceptron dengan banyak lapisan untuk mengubah bobot-bobot yang terhubung dengan neuron-neuron yang ada pada lapisan tersembunyinya (hidden layer) $[1,7,8,10]$. Arsitektur jaringan syaraf tiruan backpropagation yang digunakan dalam penelitian ini tersusun atas tiga lapisan, yaitu satu lapisan masukan (lapisan $\mathrm{X}$ ), satu lapisan tersembunyi (lapisan Z) dan satu lapisan keluaran (lapisan Y) seperti diperlihatkan pada Gambar 1.
Adapun algoritma jaringan syaraf tiruan backpropagation dalam penelitian ini adalah sebagai berikut :

- Inisialisasi bobot (ambil bobot dengan nilai random yang cukup kecil)

- Kerjakan langkah-langkah berikut selama kondisi berhenti bernilai FALSE. Untuk tiap-tiap pasangan elemen yang akan dilakukan pembelajaran kerjakan:

Langkah feedforward:

1. Tiap-tiap unit input $\left(\mathrm{X}_{i}, \mathrm{i}=1,2,3, \cdots, \mathrm{n}\right)$ menerima sinyal $\mathrm{x}$, dan meneruskan sinyal tersebut ke semua unit pada lapisan yang ada di atasnya (lapisan tersembunyi).

2. Tiap-tiap unit tersembunyi $\left(\mathrm{Z}_{j}, \mathrm{j}=1,2,3, \cdots, \mathrm{p}\right)$ menjumlahkan sinyal-sinyal input terbobot:

$$
Z_{i n, j}=v_{o j}+\sum_{i=1}^{n} x_{i} v_{i j}
$$

Gunakan fungsi aktivasi untuk menghitung sinyal outputnya :

$$
Z_{j}=f\left(Z_{i n, j}\right)
$$

Dan kirimkan sinyal tersebut ke semua unit di lapisan atasnya (unit-unit output)

3. Tiap-tiap unit output $\left(\mathrm{Y}_{k}, \mathrm{k}=1,2,3, \cdots, \mathrm{m}\right)$ menjumlahkan sinyal-sinyal input berbobot.

$$
y_{i n, j}=w_{o k}+\sum_{j=1}^{n} z_{j} w_{j k}
$$

Gunakan fungsi aktivasi untuk menghitung sinyal outputnya :

$$
y_{j}=f\left(y_{i n, k}\right)
$$

Dan kirimkan sinyal tersebut ke semua unit di lapisan atasnya (unit-unit output).

\section{Langkah backpropagation:}

4. Tiap-tiap unit output $\left(\mathrm{Y}_{k}, \mathrm{k}=1,2,3, \cdots, \mathrm{m}\right)$ menerima target pola yang berhubungan dengan pola input pembelajaran, hitung informasi errornya :

$$
\delta_{j}=\left(t_{j}-t_{k}\right) f^{\prime}\left(y_{i n, k}\right)
$$

Kemudian hitung koreksi bobot (yang nantinya akan digunakan untuk memperbaiki nilai $w_{j k}$ ):

$$
\Delta w_{j k}=\alpha \delta_{k} z_{j}
$$

Hitung juga koreksi bias (yang nantinya akan digunakan untuk memperbaiki nilai $\mathrm{w}_{0 k}$ ):

$$
\Delta w_{o k}=\alpha \delta_{k}
$$

Kirimkan $\delta_{k}$ ini ke unit-unit yang ada di lapisan bawahnya. 
5. Tiap-tiap unit tersembunyi $\left(\mathrm{Z}_{j}, \mathrm{j}=1,2,3, \cdots, \mathrm{p}\right)$ menjumlahkan delta inputnya (dari unit-unit yang berada pada lapisan di atasnya):

$$
\delta_{i n, j}=\sum_{k=1}^{m} \delta_{k} w_{j k}
$$

Kalikan nilai ini dengan turunan dari fungsi aktifasinya untuk menghitung informasi error :

$$
\delta_{j}=\delta_{i n, j} f^{\prime}\left(z_{i n, j}\right)
$$

Kemudian hitung koreksi bobot (yang nantinya akan digunakan untuk memperbaiki nilai $\mathrm{v}_{i j}$ ) :

$$
\Delta v_{j k}=\alpha \delta_{j} x_{i}
$$

Hitung juga koreksi bias (yang nantinya akan digunakan untuk memperbaiki nilai $\mathrm{v}_{o j}$ ) :

$$
\Delta v_{o j}=\alpha \delta_{j} v
$$

6. Tiap-tiap unit output $\left(\mathrm{Y}_{j}, \mathrm{j}=1,2,3, \cdots, \mathrm{m}\right) \mathrm{mem}$ perbaiki badan bobot-bobotnya $(j=1,2,3, \cdots, p)$ :

$$
w_{j k}(\text { baru })=w_{j k}(\text { lama })+\Delta w_{j k}
$$

Tiap-tiap unit tersembunyi $\left(\mathrm{Z}_{j}, \quad \mathrm{i}=1,2,3, \cdots, \mathrm{p}\right)$ memperbaiki bias dan bobotnya $(\mathrm{i}=1,2,3, \cdots, \mathrm{n})$ :

$$
w_{i j}(\text { baru })=w_{i j}(\text { lama })+\Delta w_{i j}
$$

- Tes kondisi berhenti.

\section{METODE PENELITIAN}

\section{Data Penelitian}

Data yang digunakan pada penelitian ini adalah data citra hasil foto rontgen pasien yang telah didiagnosa oleh dokter. Data ini dikelompokan menjadi data citra untuk keperluan pelatihan perangkat lunak dan data citra untuk keperluan pengujian perangkat lunak. Citra untuk pelatihan yang digunakan sebanyak 90 buah, terdiri dari 30 buah citra rontgen paru-paru keadaan normal, 30 buah citra rontgen paru-paru terkena kanker dan 30 buah citra rontgen paru-paru terkena efusi. Sedangkan citra untuk pengujian yang digunakan sebanyak 60 buah terdiri dari 20 buah citra rontgen paru-paru keadaan normal, 20 buah citra rontgen paru-paru terkena kanker dan 20 buah citra rontgen paru-paru terkena efusi. Gambar 2 memperlihatkan sebuah contoh citra rontgen paru-paru untuk masing-masing keadaan tersebut.

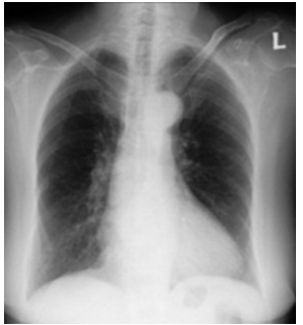

(a)

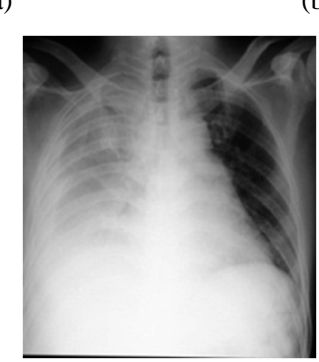

(c)

Gambar 2: Contoh citra rontgen paru-paru: (a) paru-paru normal, (b) paru-paru kanker, dan (c) paru-paru efusi.

\section{Tapis Median (Median Filter)}

Tapis Median (median filter) merupakan salah satu teknik peningkatan kualitas citra dalam domain spasial. Metode ini termasuk dalam metode non linear filtering. Median filter yang digunakan adalah blok berdimensi 9 x 9. Setiap citra memiliki noise. Noise yang ada pada citra akan mempengaruhi proses pengolahan citra ketika tidak ada perlakuan pada noise tersebut. Sehingga untuk mengurangi noise yang ada pada citra tersebut maka dilakukan proses filterisasi pada citra. Proses fiterisasi yang telah dilakukan pada penelitian ini adalah dengan menggunakan median filter.

\section{Adaptive Histogran Equalisation}

Proses ekualisasi histogram yang telah dilakukan adalah dengan menggunakan adaptive histogram equalisation. Proses ekualisasi histogram ini dilakukan agar nilai-nilai histogram pada citra merata untuk tiap bagiannya. Proses adaptive histogram equalisation sama dengan proses histogram biasa, hanya saja citra dibagi menjadi beberapa bagian, dan kemudian tiap bagian citra itu diekualisasi histogramnya, hasil dari masing-masing bagian ini akan menghasilkan nilai histogram baru yang lebih merata. Gambar 3 memperlihatkan sebuah contoh citra rontgen sebelum mendapat pemrosesan awal, dan setelah mendapat pemrosesan awal, yaitu median filter dan adaptive histogram equalisation.

\section{Ekstraksi Fitur Histogram}

Ekstraksi fitur histogram merupakan metode pengambilan ciri yang didasarkan pada karakteristik histogram citra. Histogram menunjukkan probabilitas kemunculan nilai derajat keabuan piksel pada suatu citra. Bila X menyatakan tingkat 


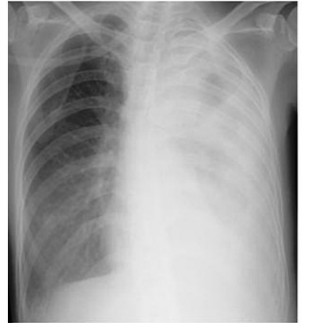

(a)

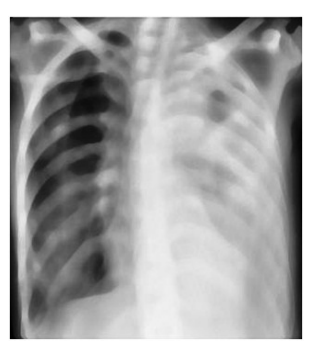

(c)

Gambar 3: Pengolahan awal: (a) citra asli, (b) citra hasil median filter, dan (c) citra hasil adaptive histogram equalisation.

keabuan pada suatu citra, maka probabilitas $\mathrm{P}(\mathrm{X})$ dinyatakan dengan:

$$
P(X)=\frac{\text { banyak titik dg tingkat keabuan }}{\text { total banyak titik pada citra }}
$$

Fitur histogram yang digunakan pada penelitian ini adalah nilai mean, standard deviasi, kurtosis, skewness dan entropy.

\section{Klasifikasi}

Proses pengklasifikasian citra pada penelitian ini dengan menggunakan jaringan syaraf tiruan backpropagation. Jaringan terlebih dahulu dilatihkan dengan citra latih. Pelatihan yang dilakukan bertujuan untuk mendapatkan nilai-nilai bobot dari jaringan. Bobot yang didapatkan akan tersimpan dan menjadi nilai yang akan digunakan untuk proses pengujian citra uji. Pada penelitian ini, jaringan syaraf tiruan digunakan untuk mengklasifikasikan citra uji kedalam kelompok tertentu yaitu kanker, efusi dan normal. Diagram alir pengujian jaringan syaraf tiruan ditunjukkan Gambar 4.

\section{HASIL DAN PEMBAHASAN}

\section{Pemrosesan Awal}

Pemrosesan awal atau disebut juga dengan pre-processing merupakan sebuah proses awal yang dilakukan untuk memperbaiki kualitas citra dan mengambil ciri atau karakteristik dari citra digital tersebut sebelum dilakukan pemrosesan lebih

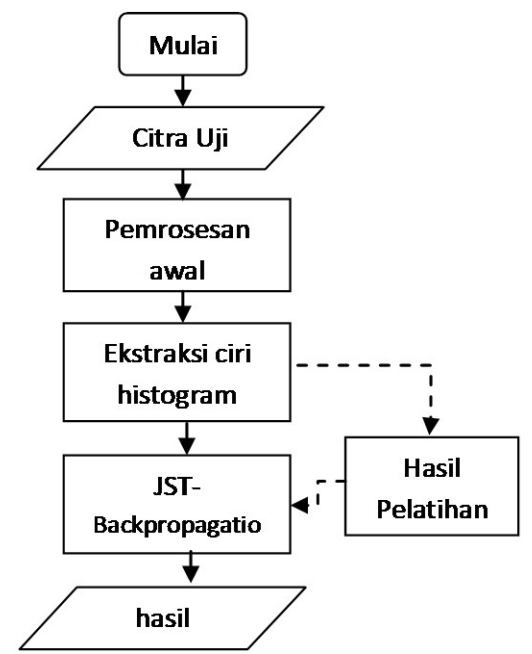

Gambar 4: Diagram Alir Pengujian.

lanjut. Dalam penelitian ini, perbaikan citra adalah proses median filter dan ekualisasi histogram adaptif. Sedangkan ciri atau karakteristik citra yang diambil dalam penelitian adalah ciri histogram masing-masing citra, yaitu : mean, standard deviasi, kurtosis, skewness dan entropy.

\section{Pengujian Jaringan Syaraf Tiruan}

Performansi jaringan diuji dengan menggunakan nilai akurasi dan error. Dimana tingkat akurasi adalah tingkat keakuratan sistem jaringan syaraf tiruan dalam mengenali inputan citra yang diberikan sehingga menghasilkan output yang benar. Secara matematis dirumuskan sebagai berikut:

$$
\text { akurasi }=\frac{\text { jumlah data yang benar }}{\text { jumlah data keseluruhan }} \times 100 \%
$$

Sedangkan untuk besar error dirumuskan sebagai berikut :

$$
\text { error }=\frac{\text { jumlah data yang salah }}{\text { jumlah data keseluruhan }} \times 100 \%
$$

Penelitian yang telah dilakukan pada sistem jaringan syaraf tiruan ini adalah dengan mengubah nilai parameterparameternya. Parameter-parameter tersebut adalah jumlah neuron pada lapisan tersembunyi (hidden layer) dan nilai epoch jaringan. Nilai-nilai parameter inilah yang diubahubah sehingga dapat diperoleh hasil yang paling baik. Pada proses pelatihan jaringan, diperoleh hasil yang berubah-ubah, karena nilai bobot awal untuk bobot awal input, bobot awal bias input, bobot awal lapisan dan bobot awal bias lapisan diatur untuk terisi secara acak, sehingga tingkat akurasi yang didapat juga berubah. Dari hasil pengujian dengan beberapa kali pengubahan parameter, akhirnya didapatkan hasil terbaik sebesar 98,9\%, seperti diperlihatkan pada Tabel I.

Dari hasil pelatihan dengan tingkat akurasi yang terbaik ini, nilai-nilai bobot dari jaringan yang diperoleh disimpan dan dijadikan parameter untuk pengujian sistem jaringan tersebut 
TABEL I: Hasil klasifikasi citra latih (epoch 370, neuron 2500, error $0,001$, learning rate 0,1$)$.

\begin{tabular}{lcccccc}
\hline \hline Citra & \multicolumn{2}{c}{ Terdeteksi sebagai } & \multicolumn{2}{c}{ Tingkat } & Error Jumlah \\
Uji & Normal & Kanker & Efusi & Akurasi & Citra \\
\hline Normal & 30 & 0 & 0 & $100 \%$ & $0 \%$ & 30 \\
Kanker & 0 & 30 & 0 & $100 \%$ & $0 \%$ & 30 \\
$\begin{array}{l}\text { Efusi } \\
\text { Rata-rata }\end{array}$ & 0 & 1 & 29 & $96,7 \%$ & $3,3 \%$ & 30 \\
prosentase & & & & & & \\
\hline
\end{tabular}

TABEL II: Hasil klasifikasi citra uji (epoch 370, neuron 2500, error $0,001$, learning rate 0,1$)$.

\begin{tabular}{|c|c|c|c|c|c|c|}
\hline Citra & Terde & teksi seb & agai & Tingkat & Error & Jumlah \\
\hline Uji & Normal & Kanker & Efusi & Akurasi & & Citra \\
\hline Normal & 15 & 5 & 0 & $75 \%$ & $25 \%$ & 20 \\
\hline Kanker & 4 & 12 & 4 & $60 \%$ & $40 \%$ & 20 \\
\hline Efusi & 1 & 7 & 12 & $60 \%$ & $40 \%$ & 20 \\
\hline $\begin{array}{l}\text { Rata-rata } \\
\text { prosentase }\end{array}$ & & & & $65 \%$ & $35 \%$ & 60 \\
\hline
\end{tabular}

[1] D. Putera, Pengolahan Citra Digital (Penerbit Andi Yogyakarta, 2010).

[2] Saksono, Hanung, dan Tyas, Pendeteksian Kanker Paru-Paru Dengan Menggunakan Transformasi Wavelet Dan Metode Linear Discriminant Analysis (Digilib Institut Teknologi Telkom, Bandung, 2010).

[3] Persify-Efusi Pleura, (URL: http://www.persify.com/id/ perspectives/ medical- conditions- diseases/efusi- pleura- 9510001 031359) (Juni-2013).

[4] R. Supriyadi - Efusi Pleura, (URL: http://rizqisupriyadi0. wordpress.com/ 2013/04/ 13/efusi-pleura/), (Juni-2013).

[5] Wikipedia - Kanker Paru-paru, (URL: http://id.wikipedia.org/ wiki/Kanker paru-paru) (Juni-2013). terhadap citra yang belum pernah dilatihkan pada jaringan. Dengan nilai parameter yang sama yaitu epoch $=370$, nilai error $=0,001$, learning rate $=0,1$ serta jumlah neuron sebanyak 2500 , sistem jaringan syaraf tiruan ini diuji dengan menggunakan data citra uji. Hasil pengujian menghasilkan tingkat akurasi rata-rata sebesar $65 \%$ seperti diperlihatkan pada Tabel II.

\section{SIMPULAN}

Sistem perangkat lunak untuk mengidentifikasi citra rontgen paru-paru ke dalam paru-paru normal, kanker dan efusi dengan ekstraksi fitur histogram dan jaringan syaraf tiruan backpropagation telah berhasil dilakukan. Hasil pelatihan sistem perangkat lunak jaringan syaraf tiruan menggunakan citra latih memperlihatkan kinerja optimumnya untuk masingmasing parameter-parameter yaitu: epoch $=370$, nilai error $=$ 0,001 , learning rate $=0,1$ dan jumlah neuron sebanyak 2500 . Hasil pemgujian sistem perangkat lunak menggunakan citra uji memperlihatkan bahwa sistem perangkat lunak memiliki performansi sebesar $65 \%$.
[6] G. Rafael, et al., Digital Image Processing Using Matlab (2 $2^{\text {nd }}$ edition, Gatesmark Publishing, USA, 2008).

[7] J. J. Siang, Jaringan Saraf Tiruan dan Pemrograman menggunakan Matlab (Penerbit Andi, Yogyakarta, 2009).

[8] S. Kusumadewi, Artificial Intelligence (Graha Ilmu, Yogyakarta, 2003).

[9] S. N. Sivanadam, and S. N. Deepa, Introducting to neural network using matlab 6.0 (McGraw-Hill Education, 1994).

[10] R. Perez-Aguila, P. Gomez-Gil, and A. Aguilera, Non-supervised Classification of 2D Color Images Using Kohonen Networks and a Novel Metric, (Universidad de las Americas, Mexico, 1989). 